\title{
SIMPÓSIO INTERNACIONAL SOBRE TEORIA E MÉTODO EM ARQUEOLOGIA
}

O Museu de Arqueologia e Etnologia da Universidade de São Paulo organizou o Simpósio Internacional sobre Teoria e Método em Arqueologia juntamente com a Universidade de Michigan (EUA) de 7 a 11 de agosto de 1995 .

A idéia inicial do Simpósio partiu de Norman Yoffee (Department of Near Eastern Studies, Museum of Anthropology/University of Michigan) $e$ de Renato Kipnis (doutorando na mesma universidade), que constituíram a Comissão Organizadora juntamente com Marisa Coutinho Afonso e Levy Figuti, ambos do MAE/USP, sob a coordenação geral de Adilson Avansi de Abreu, diretor do MAE.

$O$ evento pode ser considerado como uma continuação dos dois excelentes Simpósios internacionais realizados por Edna June Morley e Paul Fish (Universidade do Arizona) nos Estados do Rio de Janeiro e de Santa Catarina, quando questões conceituais e metodológicas foram bastante abordadas.

Os objetivos do Simpósio em São Paulo foram: propiciar a discussão sobre teorias e métodos arqueológicos; promover o intercâmbio, na área de Arqueologia, entre instituições brasileiras e a Universidade de Michigan, com relação ao ensino e à pesquisa e promover a apresentação de trabalhos arqueológicos com ênfase nas questões metodológicas.

O evento foi realizado no auditório do Instituto Oceanográfico/USP e contou com o apoio da PróReitoria de Cultura e Extensão Universitária/USP, International Institute/University of Michigan, Fundação de Amparo à Pesquisa do Estado de São Paulo (FAPESP), BANESPA/USP e Instituto Oceanográfico/USP.

Participaram do simpósio arqueólogos brasileiros, americanos e franceses de diversas instituições. Da Universidade de Michigan: Norman Yoffee, Jeffrey Parsons, Carla Sinopoli, Susan Alcock, Preston Miracle; da Universidade do Arizona: Paul Fish e Suzanne Fish; do Serviço Florestal americano (Arizona): Peter J. Pilles Jr.; do Muséum National d'Histoire Naturelle (Paris): Águeda VilhenaVialou e Denis Vialou; da Pontifícia Universidade Católica (Porto Alegre): Arno Alvarez Kern; do
Museu Nacional/UFRJ (Rio de Janeiro): Maria Dulce Gaspar e Carlos Fausto; do IPHAN/Santa Catarina: Edna June Morley; da Universidade Federal de Goiás: Irmhild Wüst; da Universidade de São Paulo (Departamento de História/FFLCH): Norberto Luiz Guarinello; da Universidade Estadual de Campinas: Pedro Paulo A. Funari; da empresa Scientia Consultoria Científica: Solange Bezerra Caldarelli; do MAE/USP: Eduardo Góes Neves, José Luiz de Morais, Levy Figuti, Maria Beatriz Florenzano e Paulo A. D. De Blasis.

O Simpósio foi organizado de modo a apresentar duas conferências, sendo uma na abertura do evento (de Norman Yoffee) e a segunda no encerramento (de Arno Alvarez Kern) além de sete mesas redondas temáticas (prospecção arqueológica e sistemas sociais; caçadores-coletores; pescadores-coletores; arqueologia histórica e clássica; etnoarqueologia; etnohistória e teoria arqueológica).

Os trabalhos apresentados abordaram temas como padrões de assentamento, organização social, zooarqueologia, etnoarqueologia, entre outros, desenvolvidos em diversas áreas geográficas como: Brasil (estados de São Paulo, Amazonas, Goiás, Rio Grande de Sul e região nordeste); América do Norte (norte do México, sudoeste e sudeste dos Estados Unidos); Grécia; Índia e França. Os aspectos teóricos e metodológicos que nortearam o desenvolvimento das pesquisas arqueológicas e etnográficas foram bastante enfocados.

O Simpósio propiciou uma reflexão necessária sobre as teorias e metodologias arqueológicas. Normalmente, nos eventos científicos de arqueologia brasileira, pouco tempo é destinado ao aprofundamento deste tipo de questões, porque se privilegia a divulgação dos trabalhos realizados. No entanto, apesar de ser fundamental a divulgação das pesquisas arqueológicas realizadas por várias equipes, também é de grande importância a discussão da própria disciplina científica nas suas diferentes abordagens teóricas e metodológicas. $\mathbf{O}$ objetivo principal do Simpósio foi dar espaço a esta discussão, o que ocorreu não só durante os debates, mas em conversas informais com os participantes e o público. 
Um aspecto altamente positivo foi a reunião no mesmo simpósio de especialistas em arqueologia americana e clássica. Em poucos eventos científicos, como em algumas reuniões da Sociedade de Arqueologia Brasileira, este entrosamento ocorreu e é interessante notar que isto tenha acontecido em um simpósio organizado por uma instituição com o perfil do MAE/USP, que reúne catorze arqueólogos (dez especialistas em arqueologia brasileira e quatro em clássica).

Em uma carta, Norman Yoffee, organizador da vinda dos americanos ao Brasil, fez uma avaliação do evento: " the symposium established a good level of cooperation in which ideas were exchanged on both sides. A number of projects are now being explored between Brazilians and Americans for archaeological work".

Quanto ao público participante, noventa e uma pessoas se inscreveram, sendo 66 do estado de São Paulo, 5 do Rio de Janeiro, 3 do Rio Grande do Sul, 2 do Paraná, 2 de Santa Catarina, 2 de Mato Grosso, 2 do Pará, 1 do Amapá, 1 de Rondônia, 1 do Rio Grande do Norte, 1 de Minas Gerais, 1 do Ceará, 2 da França, 1 do Uruguai e 1 dos Estados
Unidos; a maior parte formada por jovens arqueólogos empregados em diversas instituições e/ou realizando cursos de pós-graduação. Na realidade, houve um número maior de professores e alunos presentes, pois a inscrição não foi obrigatória para assistir às apresentações, o que ocasionou a existência de um público flutuante com interesses mais específicos.

Além do debate sobre teoria e método em arqueologia, principal objetivo do simpósio, sua importância foi, sobretudo, criar oportunidades de contatos entre os profissionais proporcionando o desenvolvimento de projetos conjuntos. Além disso, permitiu a participação de estudantes de arqueologia em discussões de alto nível.

Durante o simpósio, foi distribuído aos inscritos um Caderno de Resumos e houve a doação pelos arqueólogos da Universidade de Michigan de livros e revistas especializadas americanas ao MAE. Os vinte e três participantes foram convidados a enviar os textos apresentados no simpósio para a publicação dos Anais, que deverão constituir um número especial da Revista do Museu de Arqueologia e Etnologia a ser publicado em 1997.

Marisa Coutinho Afonso* 